Original Research Article

\title{
A questionnaire-based comparison of conventional teaching methods to computer assisted learning in experimental pharmacology for undergraduate medical students
}

\author{
Ravi Kant Tiwari*, Sandeep K. Gupta, R. K. Goel
}

Department of Pharmacology, Heritage Institute of Medical Sciences, Varanasi, Uttar Pradesh, India

Received: 05 February 2019 Accepted: 08 March 2019

*Correspondence to:

Dr. Ravi Kant Tiwari

Email: drrkt1912@gmail.com

Copyright: (C) the author(s), publisher and licensee Medip Academy. This is an openaccess article distributed under the terms of the Creative Commons Attribution NonCommercial License, which permits unrestricted noncommercial use, distribution, and reproduction in any medium, provided the original work is properly cited.

\begin{abstract}
Background: Computer Assisted Learning (CAL) for teaching experimental pharmacology is now widely accepted as alternative to animal experiments. The objective of this study was to compare the performance of undergraduate medical students by conventional teaching methods (lecture and discussion) and CAL.

Methods: This was a questionnaire based observational study involving 109 MBBS students of fifth semester. The students were taught experimental pharmacology practical by both conventional methods (lecture with discussion) and computer assisted learning (CAL). Questionnaire and their filled responses by these students were taken at the end of lecture-discussion (pre-CAL) and after the CAL experiments (post-CAL), covering the same topics of experimental pharmacology. Pre-CAL and post-CAL data were assessed statistically.

Results: In the pre-CAL session, only $53.39 \%, 47.56 \%, 53.39 \%$ and $49.5 \%$ of the students were having the scores above $40 \%$ in the rabbit eye, DRC and potentiation, frog heart and $\operatorname{dog} \mathrm{BP}$ experiment respectively, which was increased to $77.44 \%, 75.48 \%, 75.47 \%$ and $75.48 \%$ of the students respectively in the postCAL assessment. A statistically significant difference $(p<0.05)$ in the performance was observed among the students in the pre-CAL and post-CAL assessment.

Conclusions: CAL is a good alternative to animal experimentation. Lecture with discussion, followed by CAL experiments on the same topics, enhanced the performance of students as shown by improvement in post-CAL scores.
\end{abstract}

Keywords: Animal experiments, Computer assisted learning, Experimental pharmacology

\section{INTRODUCTION}

Pharmacology is both a basic as well as applied subject taught to undergraduate medical students in their $3^{\text {rd }}, 4^{\text {th }}$ and $5^{\text {th }}$ semesters. The subject encompasses the basic fundamental concept about the drugs and their effect on normal physiology as well as in the diseased states. The curriculum of undergraduate pharmacology is divided as theory lecture and practical. The practical section in pharmacology includes pharmacy, experimental and clinical pharmacology. ${ }^{1}$

As per the guidelines of UGC (University Grants Commission) and MCI (Medical Council of India), the animal experiments are banned in India for teaching purpose and these are replaced by computer models and simulation experiments. ${ }^{2}$ Simulation experiments via CAL offer the effective implementation of 3 'R's (Reduction, Refinement and Replacement) in animal experiments. ${ }^{3}$ 
Both in-vitro and in-vivo experiments were previously taught to the undergraduate medical students by using animals but experiments on CAL not only avoids the unethical sacrifice of animals, but also is time saving, costeffective, repeatable and incorporates to a better understanding and acquisition of cognitive domain of learning to the students. ${ }^{4} \mathrm{~A}$ number of studies have been conducted earlier on the perception of students about CAL as teaching method, including its advantages and disadvantages, but very few studies were conducted on the performance of the students on the major topics of experimental pharmacology at undergraduate level. ${ }^{5-9}$ The present study was aimed to evaluate the performance of students on conventional teaching methods (such as lecture and demonstration) followed by CAL experiments on the same topics of experimental pharmacology.

\section{METHODS}

This questionnaire-based study was conducted at Department of Pharmacology, Heritage Institute of Medical Sciences (HIMS), Varanasi, Uttar Pradesh, India. One hundred and nine (109) MBBS students in their fifth semester were the participants in this study. The participants were explained about the study and their participation was voluntary after obtaining the informed consent from them.

The experimental pharmacology practical was discussed in detail to these students by classroom lectures in $3^{\text {rd }}$ and $4^{\text {th }}$ semesters and by simulated experiments by CAL method in $4^{\text {th }}$ and $5^{\text {th }}$ semesters. A questionnaire consisting of four major sections which were rabbit eye experiments, DRC on frog rectus abdominis and potentiation effect of physostigmine, cardiac stimulants and depressants on isolated and perfused frog heart and dog BP experiments was prepared by the faculty members of the Department of Pharmacology, HIMS. Each section of the questionnaire comprised of five multiple choice questions (MCQs) with a single correct response, so a total of 20 questions were included in the questionnaire.

After the completion of classroom lectures on these four topics of experimental pharmacology, at the end of $4^{\text {th }}$ semester, CAL experiments were started on these same topics. The filled responses of the questionnaire from these students were collected at the end of classroom lectures but before the start of CAL experiments (pre-CAL) and at the completion of CAL experiments (post-CAL). Out of 109 students, six and seven students did not participate in the pre-CAL and post-CAL study respectively, so these were excluded from the total number of students participated in this study. After the initial 15 minutes briefing about the study, the students were provided 30 minutes time to fill the responses of the questionnaire independently. One hundred three (103) pre-CAL and 102 post-CAL filled questionnaires were collected from the students and analyzed statistically using two-sided p value at a 5\% level of significance.

\section{RESULTS}

In the section of rabbit eye experiments of the questionnaire, $46.59 \%$ of the participants were having preCAL score equal to or below $40 \%$, while in the post-CAL assessment only $22.54 \%$ of the participants were having the same score. In the pre-CAL session, only $53.39 \%$ of the participants scored above $40 \%$, this was increased to $77.44 \%$ of the participants in the post-CAL session. There was a statistically significant difference in the performance among the students in the pre-CAL and post-CAL assessment in rabbit eye experiments (chi-square statistic 15.420, p-value <0.05) (Table 1).

Table 1: Questionnaire based comparison in rabbit eye experiments.

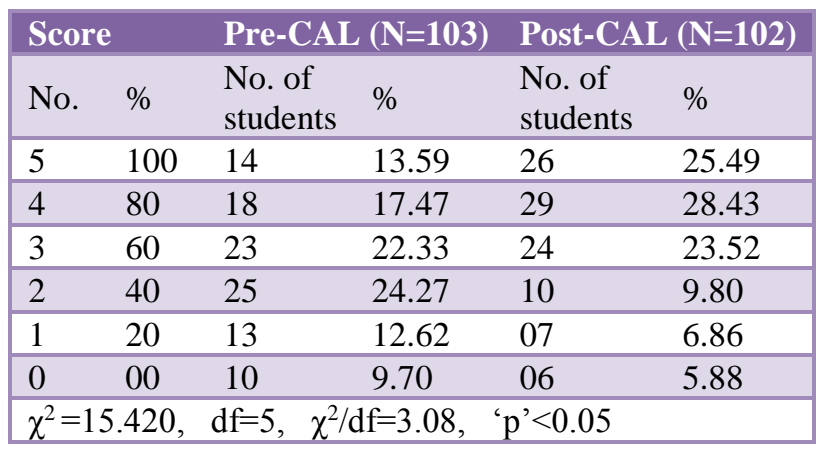

In the section of DRC and potentiation experiments on frog rectus abdominis of the questionnaire, $52.41 \%$ of the students were having pre-CAL score equal to or below $40 \%$, which was reduced to only $24.5 \%$ of the participants in the post-CAL session with similar score. In the pre-CAL session, only $47.56 \%$ of the students scored $40 \%$ and above which was increased to $75.48 \%$ of the participants in the post-CAL session. This was shown by a statistically significant difference in their performance in the pre-CAL and post-CAL assessment in DRC and potentiation experiments (chi-square statistic 18.357, p-value <0.05) (Table 2).

Table 2: Questionnaire based comparison in DRC and Potentiation experiments.

\begin{tabular}{|c|c|c|c|c|c|}
\hline \multicolumn{2}{|c|}{ Score } & \multicolumn{2}{|c|}{ Pre-CAL (N=103) } & \multicolumn{2}{|c|}{ Post-CAL ( $\mathrm{N}=102)$} \\
\hline No. & $\%$ & $\begin{array}{l}\text { No. of } \\
\text { students }\end{array}$ & $\%$ & $\begin{array}{l}\text { No. of } \\
\text { students }\end{array}$ & $\%$ \\
\hline 5 & 100 & 15 & 14.56 & 22 & 21.56 \\
\hline 4 & 80 & 13 & 12.62 & 27 & 26.47 \\
\hline 3 & 60 & 21 & 20.38 & 28 & 27.45 \\
\hline 2 & 40 & 26 & 25.24 & 11 & 10.78 \\
\hline 1 & 20 & 17 & 16.50 & 07 & 6.86 \\
\hline 0 & 00 & 11 & 10.67 & 07 & 6.86 \\
\hline
\end{tabular}

In the frog heart experiments portion of the questionnaire $46.58 \%$ of the students scored $\leq 40 \%$ which was reduced to only $24.5 \%$ of the students in the post-CAL session. Only 
$53.39 \%$ of the students scored above $40 \%$ in the pre-CAL while this was increased to $75.47 \%$ of the students in the post-CAL session. Statistically significant difference was seen in the pre-CAL and post-CAL performances in the frog heart experiments (chi-square statistic 16.123, p-value $<0.05$ ) (Table 3). In the dog BP experiment section of the questionnaire $50.47 \%$ of the students scored equal to or below $40 \%$, this was reduced to $24.5 \%$ of the students in the post-CAL session. Only $49.5 \%$ of the participants were having the pre-CAL score above $40 \%$ and this was increased to $75.48 \%$ of the students in the post-CAL session. Statistically significant difference was also seen in the pre-CAL and post-CAL performances in the dog BP experiments (chi-square statistic 15.188, p-value <0.05) (Table 4).

Table 3: Questionnaire based comparison in frog heart experiments.

\begin{tabular}{|llllll|}
\hline \multicolumn{2}{|l}{ Score } & \multicolumn{2}{l}{ Pre-CAL $(\mathbf{N}=103)$} & \multicolumn{2}{l|}{ Post-CAL $(\mathbf{N}=102)$} \\
\hline No. & $\%$ & $\begin{array}{l}\text { No. of } \\
\text { students }\end{array}$ & $\%$ & $\begin{array}{l}\text { No. of } \\
\text { students }\end{array}$ & $\%$ \\
\hline 5 & 100 & 12 & 11.65 & 25 & 24.50 \\
\hline 4 & 80 & 19 & 18.44 & 32 & 31.37 \\
\hline 3 & 60 & 24 & 23.30 & 20 & 19.60 \\
\hline 2 & 40 & 22 & 21.35 & 10 & 9.80 \\
\hline 1 & 20 & 15 & 14.56 & 07 & 6.86 \\
\hline 0 & 00 & 11 & 10.67 & 08 & 7.84 \\
\hline$\chi^{2}=16.123$, & df $=5, \quad \chi^{2} / \mathrm{df}=3.22$, & 'p'<0.05 \\
\hline
\end{tabular}

Table 4: Questionnaire based comparison in dog BP experiments.

\begin{tabular}{|llllll|}
\hline \multicolumn{2}{|l}{ Score } & \multicolumn{3}{l}{ Pre-CAL $(\mathbf{N}=103)$} & \multicolumn{2}{l|}{ Post-CAL $(\mathbf{N}=102)$} \\
\hline No. & $\%$ & $\begin{array}{l}\text { No. of } \\
\text { students }\end{array}$ & $\%$ & $\begin{array}{l}\text { No. of } \\
\text { students }\end{array}$ & $\%$ \\
\hline 5 & 100 & 13 & 12.62 & 22 & 21.56 \\
\hline 4 & 80 & 17 & 16.50 & 26 & 25.49 \\
\hline 3 & 60 & 21 & 20.38 & 29 & 28.43 \\
\hline 2 & 40 & 19 & 18.44 & 09 & 8.82 \\
\hline 1 & 20 & 18 & 17.47 & 10 & 9.80 \\
\hline 0 & 00 & 15 & 14.56 & 06 & 5.88 \\
\hline$\chi^{2}=15.188$, & df $=5, \quad \chi^{2} / \mathrm{df}=3.04$, & 'p'<0.05 \\
\hline
\end{tabular}

\section{DISCUSSION}

This questionnaire-based study compared the performance of undergraduate medical students by conventional teaching methods (lecture and discussion) with CAL, by giving a questionnaire at the end of teaching sessions on the same topics of experimental pharmacology by both conventional teaching methods and CAL. It was observed that the students taught by CAL method after the discussion of topics by lecture and discussion scored better. There was a statistically significant difference $(p<0.05)$ in the performance among the students in the pre-CAL and postCAL assessment in all the four sections of the questionnaire incorporating the rabbit eye, DRC and potentiation, frog heart and $\operatorname{dog}$ BP experiments. The findings of this study were consistent with similar studies conducted earlier. ${ }^{10}$

\section{Advantages of CAL}

CAL experiments enable the students to complete the major 5-6 simulated experiments in one- or two-month's schedule with rotation of batches. It is much less expensive than animal experiments, because it minimizes the costs for animal procurement, expenditure on their diet, maintenance and care at the animal house. ${ }^{11,12}$ The CAL experiments can be repeated two to three times in a year for revision purpose and better understanding without any extra monetary burden. The longer experiments such as three point or four-point bioassay usually takes about 3-4 hours on animal tissue but only about one hour in CAL. The total batch of 100-200 students can perform 5-6 different CAL experiments on different computers simultaneously which is practically impossible with animal experiments. Experimental errors due to biological variation or methodological errors commonly encountered during animal experiments but are totally excluded in CAL experiments. ${ }^{13}$ The CAL experiments help in better understanding of the theoretical concepts, if performed simultaneously or just after theoretical lecture and discussion. CAL experiments help in improvement of cognitive skill rather than psychomotor skill. In short, CAL is time saving, cost effective, minimizes the errors, easy to perform and helps in the better understanding. ${ }^{14,15}$

\section{Disadvantages of CAL}

The software available for CAL experiments has a fixed pattern in the experiments that can be rarely altered or changed. The students have to follow that fixed pattern and they are never exposed to the biological or methodological variation as observed in animal experiments. CAL minimizes the acquisition of psychomotor or technical skill. ${ }^{16}$

\section{CONCLUSION}

It was concluded that CAL is a welcome change as alternative to animal experiments. CAL helps in better understanding of the fundamental concepts and further if combined with theoretical discussion.

Funding: No funding sources

Conflict of interest: None declared

Ethical approval: The study was approved by the Institutional Ethics Committee

\section{REFERENCES}

1. Sudha J. Graduate Training Programmes in Pharmacology in India. Health Admin. 2006;19(1):8891.

2. Vadivelan R, Santilna KS, Elango K, Sirisha S. Alternatives to animal experimentation in teaching 
pharmacology: computer assisted learning techniques in Pharmacy curriculum. Ind J Pharmacy Pharmacol. 2015;2(1):70-3.

3. The Gazette of India. Extraordinary. part III- Section 4 (No. 88). New Delhi, Wednesday, March 19, 2014/Phalguna 28, 1935. Establishment of Medical College Regulations, 1999-Animal House. Medical Council of India Notification. New Delhi, 2014 (No.MCI-34(41)/2013-Med./64020). Available at: https://www.mciindia.org/documents/e_Gazette_Am endments/estt-new-med-col-regulation-1999.pdf. Accessed 19 April 2018.

4. Hughes IE. Do computer simulations of laboratory practicals meet learning needs?. Trends Pharmacol Sci. 2001;22(2):71-4.

5. Nettah S. Computer assisted learning (CAL) as a teaching learning method in teaching experimental pharmacology. Int J Basic Clin Pharmacol. 2014;3:635.

6. Sharma D, Malhotra P. A comparison of computer assisted learning and practical animal experiment for undergraduate medical students in pharmacology curriculum-a questionnaire-based study conducted in a medical college of North India. Inter J Basic Clin Pharmacol. 2016;5(6):2581-4.

7. Govindaraja C, Prakash HJ, Annamalai C, Vedhavathy SS. Computer assisted learning: Perceptions and knowledge skills of undergraduate medical students in a Malaysian medical school. National J Physiol Pharm Pharmacol. 2011;1(2):63.

8. Gaikwad N, Tankhiwale S. Interactive E-learning module in pharmacology: a pilot project at a rural medical college in India. Persp Med Edu. 2014;3(1):15-30.

9. Leathard HL, Dewhurst DG. Comparison of the costeffectiveness of a computer-assisted learning program with a tutored demonstration to teach intestinal motility to medical students. ALT-J. 1995;3(1):11825 .
10. Jain S, Sharma K, Jain P, Singh S. Computer assisted learning versus conventional teaching: a questionnaire-based study. Int J Basic Clin Pharmacol. 2017;6:1399-404.

11. Kuruvilla A, Ramalingam S, Bose AC, Shastri GV, Bhuvaneswari K, Amudha G. Use of computer assisted learning as an adjuvant to practical pharmacology teaching: Advantages and limitations. Ind J Pharmacol. 2001;33(4):272-5.

12. Tikoo D, Gupta M. Student's perception and experience of computer assisted learning as a teaching method in experimental pharmacology. Int $\mathrm{J}$ Basic Clin Pharmacol, 2015;4(6):1168-74.

13. Dewhurst DG, Hardcastle J, Hardcastle PT, Stuart E. Comparison of a computer simulation program and a traditional laboratory practical class for teaching the principles of intestinal absorption. Adv Physiol Edu. 1994;267(6):S95.

14. John LJ. A review of computer assisted learning in medical undergraduates. J Pharmacol Pharmacotherapeutics. 2013;4(2):86.

15. Sewell RD, Stevens RG, Lewis DJ. Pharmacology experimental benefits from the use of computerassisted learning. Am $\mathbf{J}$ Pharmaceut Edu. 1996;60(3):303-7.

16. Dewhurst D. Is it possible to meet the learning objectives of undergraduate pharmacology classes with non-animal models?. AATEX. 2007;14:207-12.

Cite this article as: Tiwari RK, Gupta SK, Goel RK. A questionnaire-based comparison of conventional teaching methods to computer assisted learning in experimental pharmacology for undergraduate medical students. Int J Basic Clin Pharmacol 2019;8:762-6. 


\section{Appendix}

Questionnaire for pre-CAL and post-CAL assessment of Experimental Pharmacology Practical

Instructions:

- Participation in this questionnaire-based study is voluntary

- Do not write your name or roll number

- Tick mark on only one response of each question

- Attempt all the questions in the given sequence on questionnaire

Section A (Rabbit eye experiments: miotic, mydriatic and local anaesthetic)

1) Passive mydriasis and abolished light reflex is seen with

(a) Atropine (b) Phenylephrine (c) Pilocarpine (d) Lignocaine

2) Active miosis is seen with

(a) Atropine (b) Phenylephrine (c) Pilocarpine (d) Lignocaine

3) Abolished corneal reflex is seen with

(a) Atropine (b) Phenylephrine (c) Pilocarpine (d) Lignocaine

4) Active mydriasis is seen with

(b) Atropine (b) Phenylephrine (c) Pilocarpine (d) Lignocaine

5) Blockade of dilator pupillae and unopposed action of sphincter pupillae results in

(a) Active miosis (b) Active mydriasis (c) Passive miosis (d) Passive mydriasis

Section B (DRC and Potentiation experiments on frog rectus abdominis)

6) In a $\log \mathrm{DRC}$ the graph/curve obtained is

(a) hyperbolic (b) S-shaped (c) L-shaped (d) Bell shaped

7) In the Potentiation effect, the changes observed in log DRC (a) left shift (b) right shift (c) flattening (D) unchanged

8) The first dose which elicits the maximum biological response in a tissue is called (a) threshold dose (b) ceiling dose (c) loading dose (d) minimum dose

9) The PSS used in frog rectus abdominis experiment

(a) Frog Ringer (b) Tyrode (c) Ringer Locke (d) De-jalon

10) In frog rectus abdominis experiment, the receptor involved for the action of acetylcholine is (a) $\mathrm{N}_{\mathrm{N}}$ (b) $\mathrm{N}_{\mathrm{M}}$ (c) $\mathrm{M}_{2}$ (d) $\mathrm{M}_{3}$

Section $\mathbf{C}$ (cardiac stimulants and depressants in frog heart experiments)

(11) Positive chronotropic action is due to these receptors

(a) $\beta 1$ (b) $\beta 3$ (c) M1 (d) M3

(12) Systolic arrest of prolonged duration is produced by

(a) $\mathrm{KCl}$ (b) $\mathrm{CaCl}_{2}$ (c) acetylcholine (d) $\mathrm{MgSO}_{4}$

(13) Diastolic arrest of prolonged duration is produced by

(a) $\mathrm{KCl}$ (b) $\mathrm{CaCl}_{2}$ (c) adrenaline (d) $\mathrm{BaCl}_{2}$

(14) Effect of cholinomimetics in heart

(a) Positive chronotropic and positive inotropic effect

(b) Negative chronotropic and negative inotropic effect

(c) Positive chronotropic and negative inotropic effect

(d) Negative chronotropic and positive inotropic effect

(15) In the presence of atropine, effect of all of these drugs can be observed except

(a) Acetylcholine (b) adrenaline (c) $\mathrm{KCl}$ ( d) $\mathrm{CaCl}_{2}$

Section D (Dog BP experiments)

(16) Biphasic action on BP is observed with

(a) Epinephrine (b) Norepinephrine (c) atropine (d) isoprenaline

(17) Dale's vasomotor reversal is not seen with Norepinephrine due to lack of action at

(a) $\alpha 1$ receptor (b) $\beta 1$ receptor (c) $\alpha 2$ receptor (d) $\beta 2$ receptor

(18) Cardiovascular actions of Norepinephrine are

(a) $\downarrow$ HR and $\downarrow$ BP (b) $\uparrow$ HR and $\uparrow B P$ (c) $\downarrow$ HR and $\uparrow B P$ (d) $\uparrow H R$ and $\downarrow$ BP

(19) Cardiovascular actions of Isoprenaline are

(a) $\downarrow$ HR and $\downarrow$ BP (b) $\uparrow \mathrm{HR}$ and $\uparrow \mathrm{BP}$ (c) $\downarrow$ HR and $\uparrow \mathrm{BP}$ (d) $\uparrow \mathrm{HR}$ and $\downarrow \mathrm{BP}$

(20) Observations of nicotinic actions of acetylcholine are

(a) $\downarrow$ HR and $\downarrow \mathrm{BP}$ (b) $\uparrow \mathrm{HR}$ and $\uparrow \mathrm{BP}$ (c) $\downarrow \mathrm{HR}$ and $\uparrow \mathrm{BP}$ (d) $\uparrow \mathrm{HR}$ and $\downarrow \mathrm{BP}$ 